\title{
SINGLE AND MULTIVESSEL PORT-ACCESS CORONARY ARTERY BYPASS GRAFTING WITH CARDIOPLEGIC ARREST: TECHNIQUE AND REPRODUCIBILITY
}

Daniel S. Schwartz, MD

Greg H. Ribakove, MD

Eugene A. Grossi, MD

Jess D. Schwartz, MD

Patricia M. Buttenheim, MA

F. Gregory Baumann, $\mathrm{PhD}$

Stephen B. Colvin, MD

Aubrey C. Galloway, MD

\begin{abstract}
Objectives: Although minimally invasive coronary artery bypass grafting is now feasible, using this technique to perform anastomoses on the beating or fibrillating heart may yield poorer graft patency than the standard open techniques that use cardioplegic arrest. This study tested the feasibility and anastomotic reproducibility of minimally invasive coronary bypass using newly developed port-access coronary artery bypass technology (Heartport, Inc., Redwood City, Calif.), which allows endovascular cardiopulmonary bypass, cardiac venting, aortic occlusion, and cardioplegic arrest for internal thoracic artery-coronary artery anastomoses. Methods: Nineteen dogs had thoracoscopic takedown of either single $(n=14)$ or bilateral $(n=$ 5) internal thoracic arteries followed by minimally invasive coronary bypass with cardioplegic arrest, done by means of the port-access system. The anastomotic technique was modified after the fourth animal by switching from a microscope to a $2.5 \mathrm{~cm}$ oval port and performing a conventional anastomosis with operative loupes. The adequacy of delivery of cardioplegic solution, ventricular decompression, and anastomotic patency was assessed. Results: The crossclamp and bypass times were $50 \pm 15$ minutes and $87 \pm 28$ minutes (mean \pm standard deviation), respectively. The mean myocardial temperature after cardioplegia was $17^{\circ} \pm 1^{\circ} \mathrm{C}$ and the aortic pressure $(-3 \pm 9 \mathrm{~mm} \mathrm{Hg})$ and pulmonary artery pressure $(4 \pm$ $1 \mathrm{~mm} \mathrm{Hg}$ ) were low throughout the procedure. All animals were weaned from bypass without inotropic agents. Angiograms and autopsies demonstrated successful thoracic artery takedown and anastomotic patency in 18 of 19 animals, with $100 \%$ anastomotic patency after the technique had been modified after the fourth animal. Conclusion: This study describes a reproducible technique for minimally invasive coronary bypass that allows myocardial protection, anastomotic precision, and predictable thoracic artery graft patency. Clinical trials are indicated. (J Thorac Cardiovasc Surg 1997;114:46-52)
\end{abstract}

$\Lambda^{\text {lthough conventional coronary artery bypass }}$ Agrafting ( $\mathrm{CABG}$ ) is far more invasive than procedures performed in the cardiac catheterization

From the Department of Surgery, Division of Cardiothoracic Surgery, New York University Medical Center, New York, N.Y.

Supported in part by a grant from Heartport, Inc., Redwood City, Calif. G.H.R. has a small equity position in Heartport, Inc.

Received for publication August 30, 1996; revisions requested Dec. 20, 1996; revisions received Feb. 3, 1997; accepted for publication Feb. 3, 1997.

Address for reprints: Greg H. Ribakove, MD, New York University Medical Center, 530 First Ave., Suite 6D, New York, NY 10016.

Copyright (C) 1997 by Mosby-Year Book, Inc.

$0022-5223 / 97 \$ 5.00+0 \quad \mathbf{1 2 / 1 / 8 0 9 3 8}$ laboratory, such as percutaneous transluminal coronary angioplasty, coronary atherectomy, or coronary stenting, the advantages of conventional CABG include excellent long-term patency rates of the internal thoracic artery (ITA) graft of $90 \%$ to $95 \%$ at 10 years and improved occurrence-free survival. ${ }^{1-8}$ Long-term results with conventional CABG are favorable when compared with the $30 \%$ to $40 \%$ early restenosis rate after angioplasty and the $20 \%$ early restenosis rate found after coronary stenting., 3,9-14 Despite the long-term benefits of CABG, however, most patients with single or double vessel disease are treated initially with catheterbased intervention, ${ }^{1,9,10}$ primarily because it is less invasive with less pain and a shorter recovery time. Several groups have described less invasive tech- 
niques of limited-thoracotomy coronary operations that involve ITA grafting on the beating or fibrillating heart, with or without cardiopulmonary bypass (CPB) ${ }^{15-19}$ Unfortunately, such anastomoses are predictably less precise than obtainable when operating on an arrested heart, which may neutralize the long-term benefits of using the ITA graft. Until recently, minimally invasive CABG with cardioplegic arrest was not possible because of limitations in percutaneous perfusion technology, operative exposure, suturing techniques through the closed chest, and, most important, the lack of a percutaneous myocardial protection system. Recent studies by Stevens and coworkers ${ }^{20,21}$ at Stanford University and from our laboratory, ${ }^{22}$ however, have demonstrated the effectiveness of closed chest cardioplegic arrest using a newly developed endovascular CPB system (EndoCPB, Heartport, Inc., Redwood City, Calif.) with an endovascular aortic occluder (Endoaortic Clamp, Heartport) and determined that minimally invasive $\mathrm{CABG}$ is possible with this technology. The present study was done to test in animals the reproducibility of the port-access CABG system (Heartport) in combination with thoracoscopic ITA dissection and CABG to the left anterior descending (LAD) artery and to determine if a high degree of anastomotic precision and graft patency is achievable with this approach.

\section{Materials and methods}

Nineteen heartworm-free mongrel dogs (25 to $30 \mathrm{~kg}$ ) were supported with $\mathrm{CPB}$ with the use of the EndoCABG System and Endoaortic Clamp for aortic occlusion and endovascular delivery of cardioplegic solution and an endovascular pulmonary artery venting catheter (EPV, Heartport) for pulmonary artery venting. All animals were given humane care in compliance with the "Principles of Laboratory Animal Care" formulated by the National Society for Medical Research and the "Guide for the Care and Use of Laboratory Animals" prepared by the Institute of Laboratory Animal Resources and published by the National Institutes of Health (NIH Publication No. 86-23, revised 1985). Results are presented as the mean \pm one standard deviation.

Surgical preparation. All animals were initially anesthetized with a $4 \%$ solution of thiamylal $(0.5 \mathrm{mg} / \mathrm{kg})$ and maintained on metacurine iodide $(0.5 \mathrm{mg} / \mathrm{kg})$ and isoflurane after endotracheal intubation with a double-lumen tube. The animals were supported by a mechanical ventilator with oxygen, and the isoflurane was titrated to blood pressure and heart rate. The condition of all animals was monitored throughout the entire procedure with electrocardiography and measurement of carotid arterial pressure with a micromanometer (Konigsberg Instruments Inc., Pasadena, Calif.), pulmonary artery and central venous pressures with a pulmonary artery catheter (Ar- row, Reading, $\mathrm{Pa}$.), and oxygen saturation with an external pulse oximeter.

ITA dissection. After induction of anesthesia, each animal was positioned in a 30-degree left lateral thoracotomy position. By means of an endotracheal tube with a bronchial blocker, the left lung was selectively deflated. A thoracoscope was placed through a $10 \mathrm{~mm}$ thoracic port, which was inserted into the sixth intercostal space (ICS) in the anterior axillary line. Instruments for performing the ITA dissection were placed through $10 \mathrm{~mm}$ thoracic ports inserted into the left third and fourth ICSs in the midaxillary line. The left ITA pedicle was dissected from its origin to its bifurcation as follows (Fig. 1, $A$ ). An incision with a thoracoscopic cautery was made longitudinally lateral to the ITA pedicle. The ITA was dissected by means of a combination of blunt and sharp dissection with the blade of the cautery. When branches were identified, small hemoclips or the electrocautery, or both, were used to divide them. The thoracoscope was moved to the third or fourth ICS ports, if necessary, for distal dissection. In five animals the right ITA was taken down in a similar fashion. Exposure was facilitated, however, by intermittent decreases in the tidal volume. The animals were systemically heparinized $(100 \mathrm{U} / \mathrm{kg})$, and, with the aid of a large endoscopic hemoclip applier, two hemoclips were placed on the most distal portions of the ITA pedicle. Before division of the ITAs from their distal attachments, an atraumatic bulldog clamp was placed thoracoscopically on the proximal portion of the artery. With the use of diathermy scissors, the ITA pedicles were divided between the large hemoclips and were withdrawn through the third or fourth ICS ports and injected with papaverine. The distal end of the pedicle was prepared outside the chest in a standard beveled fashion for anastomosis to the LAD or circumflex artery (Fig. 1, B).

Catheter placement technique. The animals were supported by CPB as described previously. ${ }^{20,22}$ In brief, a femoral venous catheter (17F cannula, model 58517, DLP, Inc., Grand Rapids, Mich.) was placed through a left femoral venous cutdown and fluoroscopically guided (MCA 30, Ratheon, Tokyo, Japan) over a guide wire to a position just within the superior vena cava. A femoral arterial cannula (14F, model 57414, DLP) was placed into the left femoral artery. These catheters were connected to the bypass pump (Shiley S-100A Bubble Oxygenator, Shiley, Inc., Irvine, Calif.; and Pemco roller pump, model 5745, Pemco, Inc., Cleveland, Ohio) in a standard fashion. An endovascular pulmonary artery venting catheter (EPV, Heartport) was inserted into the external jugular vein and guided into position over a flow-directed pulmonary artery balloon catheter by means of fluoroscopy. The pulmonary artery venting catheter served the dual purpose of monitoring pulmonary artery pressure while in line with a pressure manometer and decompressing the left ventricle during $\mathrm{CPB}$.

An endovascular aortic catheter (Endoaortic Clamp, Heartport) was positioned under fluoroscopic guidance via the femoral artery into the ascending aorta with the use of a guide wire and dilator. The endovascular aortic catheter is a triple-lumen catheter with an inflatable balloon at its distal end. Positioning of the balloon was initially confirmed with instillation of a small aliquot of 

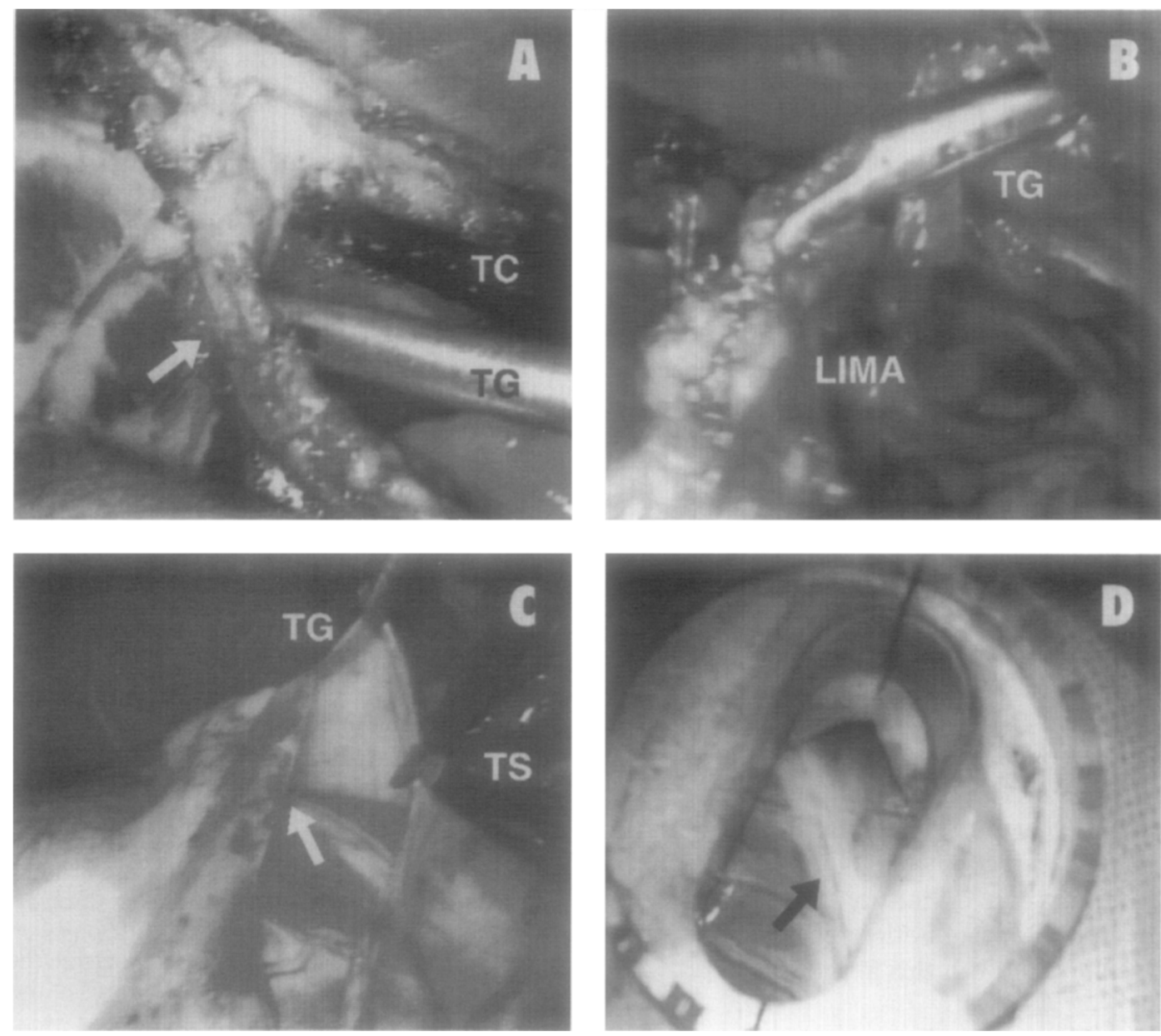

Fig. 1. A, A thoracoscopic cautery was used to dissect the left and right ITAs from the left-sided chest ports. Downward gentle traction was applied with a thoracoscopic grasper. The ITA (arrow) was dissected from the most proximal to distal extent beyond the bifurcation of the vessel. $\mathbf{B}$, The distal end of the ITA pedicle was brought through the lateral chest port for preparation of the ITA for distal anastomosis to its respective coronary arteries. LIMA, Left ITA. C, A longitudinal opening was made in the pericardium with dissecting thoracoscopic scissors and a thoracoscopic grasper. The arrow points to the medial edge of the pericardium. D, A $20 \mathrm{~mm}$ thoracic oval port was inserted through an intercostal space in the anterior chest wall over the LAD artery (arrow), and the distal anastomosis was performed under direct vision with operative loupes. $T C$, Thoracoscopic cautery; $T G$, thoracoscopic grasper; $T S$, thoracoscopic scissors.

dilute radiopaque contrast medium (Hypaque sodium, Sanofi Winthrop Pharmaceuticals, New York, N.Y.) through the central lumen, which communicates with the tip of the catheter positioned in the aortic root. The balloon, inflated by means of the second lumen, provided an endovascular "crossclamp" by occluding the ascending aortic outflow tract (Fig. 2, $A$ ). The balloon was positioned so that it rested in the aorta without occlusion of the coronary ostia or aortic arch vessels (Fig. 2, B). Proper placement of the balloon was confirmed by the instillation of approximately $10 \mathrm{ml}$ of $50 \%$ radiopaque contrast material through the central lumen into the aortic root while the balloon was inflated. The position of the endovascular aortic catheter was also reevaluated before deflation of the balloon at the end of crossclamping. Car- dioplegic solution was delivered through the central lumen, which also acted as an aortic root vent. Aortic root pressure was monitored through a third separate lumen.

CPB and delivery of cardioplegic solution. All animals were cooled to a temperature of $28^{\circ} \mathrm{C}$ and supported with CPB at flow rates of approximately $100 \mathrm{ml} / \mathrm{kg}$ per minute. Arterial oxygen tension was maintained at greater than 70 $\mathrm{mm} \mathrm{Hg}$, and the mean arterial pressure during CPB was maintained at greater than $60 \mathrm{~mm} \mathrm{Hg}$ by adjusting CPB flow. Venous return was aided by attachment of the return venous cannula to a centrifugal pump (Bio-pump, Medtronic Bio-Medicus, Eden Prairie, Minn). The ascending aorta was occluded by inflation of the balloon at the end of the endovascular aortic catheter, and multiple doses of cardioplegic solution were delivered antegradely 
through the central lumen of the catheter. All animals received Freme's cardioplegic solution mixed 4:1 with oxygenated blood and cooled to $28^{\circ} \mathrm{C}$ in a BCD Plus Heat Exchanger (Shiley). A $20 \mathrm{ml} / \mathrm{kg}$ high-potassium dose (20 to $24 \mathrm{mEq} / \mathrm{L}$ final concentration) was given initially to arrest the heart, followed by a $10 \mathrm{ml} / \mathrm{kg}$ low-potassium mixture ( 8 to $12 \mathrm{mEq} / \mathrm{L}$ final concentration) given at 15-minute intervals. All doses were given at a rate of 75 $\mathrm{ml} / \mathrm{min}$. The pulmonary artery and the aortic root were vented throughout $\mathrm{CPB}$ and drained into the oxygenator reservoir. Pressures were measured throughout CPB to ensure proper decompression of the right and left ventricles.

Coronary artery anastomosis. After the institution of $\mathrm{CPB}$ and cardioplegic arrest, the pericardium was opened longitudinally by means of the thoracoscope and an endoscopic grasper and diathermy scissors (Fig. 1, C). Care was taken so that the phrenic nerve was not injured. In the beginning of this study the coronary artery anastomosis was performed with the aid of an operating microscope placed through a thoracic port via the anterior chest wall. Two sets of operating instrument were placed on either side of the microscope, and the anastomosis was completed through these small ports. After the initial four studies, the microscope was abandoned because it proved labor intensive and awkward. The LAD or the circumflex artery, or both, was visualized through a $20 \mathrm{~mm}$ port incision made in the anterior chest wall with operating loupes (Fig. $1 D$ ). The skin, subcutaneous tissues, and ribs were separated with an $20 \mathrm{~mm}$ oval thoracic port (Oval Port, Heartport). The pericardium was elevated with sutures brought out through the anterior chest incision. Elevating the pericardium brought the LAD or circumflex artery into view through the anterior chest port. The left ITA, and in five animals both the left and right ITAs, was passed back into the chest and positioned over the corresponding coronary artery. The anastomosis was completed by means of standard suturing techniques with 7-0 polypropylene sutures. Using standard open operative techniques through the oval port offered the advantages of better operative exposure and visualization and better operative precision; the techniques were comfortable and less labor intensive than other methods.

During the final anastomosis, the blood temperature was warmed to above $35^{\circ} \mathrm{C}$ and the aorta was unclamped at completion of the anastomosis. If necessary, the heart was defibrillated with external paddles. The heart was then allowed to rewarm to $37^{\circ} \mathrm{C}$, while the pulmonary artery and aortic root were still being vented. After the animal was weaned from CPB, coronary angiograms were performed by means of an ITA Angiocath catheter (Deseret Medical, Sandy, Utah) to assess patency of the ITA grafts. All angiograms were digitized and recorded on videotape.

\section{Results}

Operative data. Eighteen of 19 animals underwent successful port-access CABG with CPB and cardioplegic arrest. One of 23 ITAs was unsuccessfully dissected and proved too short to allow performance of an anastomosis. Two adverse events oc-
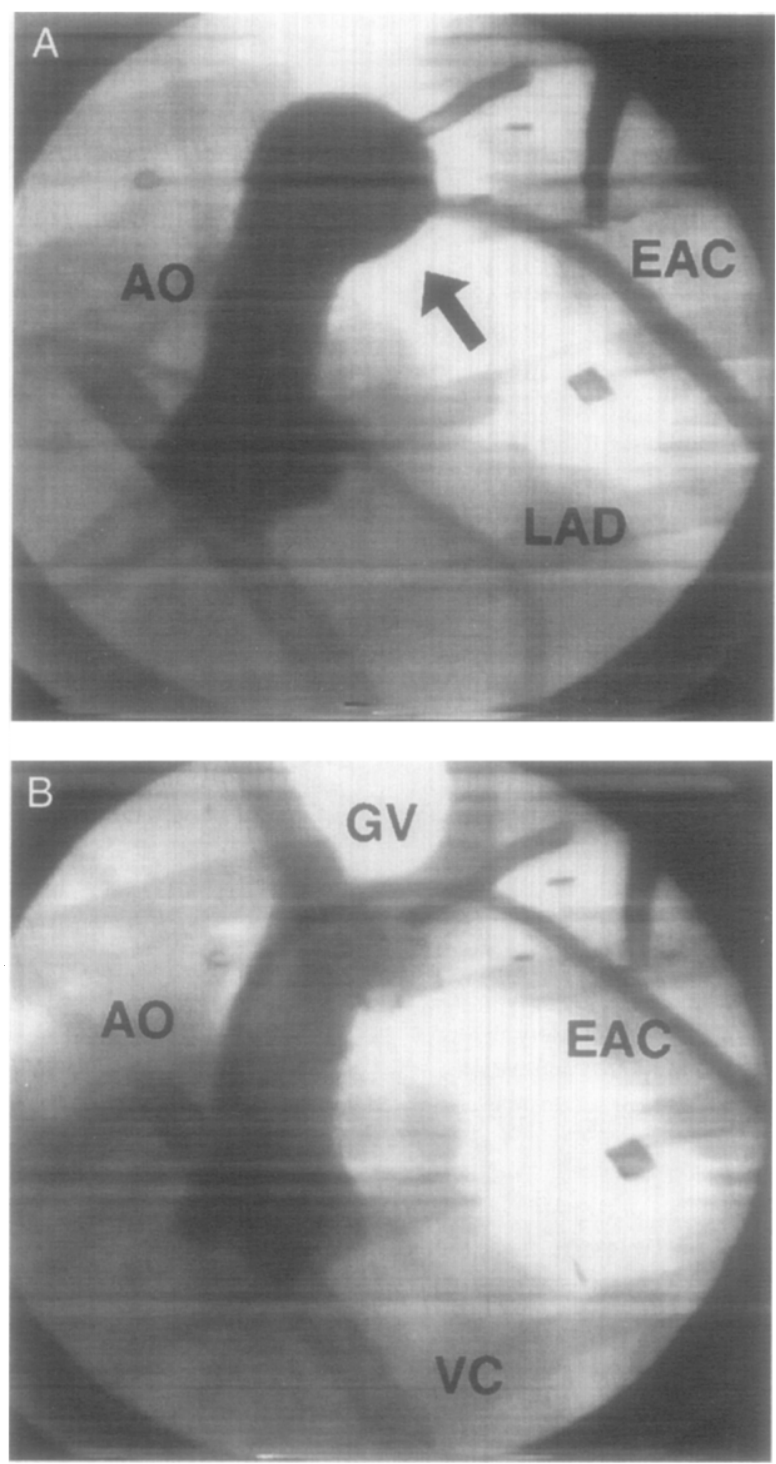

Fig. 2. A, Still frame from an angiogram demonstrating proper position of the endovascular aortic clamp $(E A C)$ balloon (arrow) in the ascending aorta $(A O)$ with complete occlusion. Note the antegrade filling of the LAD artery and the cusps of the aortic valve. B, Still frame from an angiogram confirming the endovascular aortic clamp position in relationship to the aortic $(A O)$ great arch vessels $(G V)$. The venous drainage catheter $(V C)$ is visualized inferiorly.

curred in our early studies. In one animal the ITA was short and there was excessive tension on the anastomosis. During a separate case, the balloon of the endovascular aortic clamp ruptured. This problem was immediately identified by several monitoring parameters: the differential pressure between 
Table I. Study data

\begin{tabular}{|c|c|c|c|c|c|c|c|c|}
\hline Study No. & $\begin{array}{l}\text { Artery } \\
\text { grafted }\end{array}$ & $\begin{array}{c}\text { CBP time } \\
\text { (min) }\end{array}$ & $\begin{array}{c}\text { Crossclamp } \\
\text { time } \\
\text { (min) }\end{array}$ & $\begin{array}{l}\text { PA vent } \\
\text { pressure } \\
\text { (mm Hg) }\end{array}$ & $\begin{array}{l}\text { Ao vent } \\
\text { pressure } \\
\text { (mm } \mathrm{Hg} \text { ) }\end{array}$ & $\begin{array}{l}\text { Balloon } \\
\text { pressure } \\
\text { (mm Hg) }\end{array}$ & $\begin{array}{c}\text { Adverse } \\
\text { event }\end{array}$ & $\begin{array}{c}\text { Bypass } \\
\text { successful }\end{array}$ \\
\hline 1 & LITA & 90 & 50 & 4 & 5 & 550 & No & Yes \\
\hline 2 & LITA & 90 & 55 & 6 & 0 & 520 & No & Yes \\
\hline 3 & LITA & 120 & 90 & 6 & 1 & 508 & Yes* & No末 \\
\hline 4 & LITA & 90 & 60 & 4 & -1 & 510 & Yes* & Yes \\
\hline 5 & BITA & 170 & 55 & 3 & -10 & 560 & No & Yes \\
\hline 6 & LITA & 79 & 36 & 3 & 4 & 605 & Yes $\dagger$ & Yes \\
\hline 7 & LITA & 93 & 59 & 2 & -20 & 435 & No & Yes \\
\hline 8 & LITA & 84 & 57 & 2 & -15 & 570 & No & Yes \\
\hline 9 & LITA & 74 & 47 & 2 & -21 & 475 & No & Yes \\
\hline 10 & LITA & 51 & 44 & 1 & -20 & 465 & No & Yes \\
\hline 11 & LITA & 33 & 28 & 5 & 0 & 540 & No & Yes \\
\hline 12 & LITA & 70 & 45 & 4 & 0 & 555 & No & Yes \\
\hline 13 & LITA & 85 & 30 & 4 & 2 & 460 & No & Yes \\
\hline 14 & LITA & 90 & 36 & 5 & -1 & 460 & No & Yes \\
\hline 15 & BITA & 120 & 65 & 4 & 0 & 450 & No & Yes \\
\hline 16 & BITA & 67 & 60 & 5 & 6 & 450 & No & Yes \\
\hline 17 & BITA & 84 & 58 & 4 & 3 & 530 & No & Yes \\
\hline 18 & BITA & 80 & 50 & 3 & 7 & 540 & No & Yes \\
\hline 19 & LITA & 85 & 30 & 4 & -3 & 460 & No & Yes \\
\hline Mean & & 87 & 50 & 4 & -3 & 508 & & \\
\hline SD & & \pm 28 & \pm 15 & \pm 1 & \pm 9 & \pm 50 & & \\
\hline
\end{tabular}

$C P B$, Cardiopulmonary bypass; $P A$, pulmonary artery; $A$, aortic root; $L I T A$, left internal thoracic artery; $B I T A$, bilateral internal thoracic artery; $S D$, standard deviation.

*Internal thoracic artery short.

$\dagger$ Balloon ruptured and replaced.

$\ddagger$ Procedure not successfully completed because of inadequate internal thoracic artery.

the aortic root and systemic pressure was lost, the balloon pressure fell to zero, the left ventricle distended, and an increased amount of blood was noted at the LAD arteriotomy. The endovascular aortic clamp was removed, replaced, and properly positioned. The remainder of the operation continued uneventfully.

The mean operative times and monitoring data are summarized in Table I. The mean crossclamp time was $50 \pm 15$ minutes, and our operative times improved with experience. By the end of the study we were able to perform bilateral ITA harvest and anastomosis in the same amount of time as was required to perform single ITA harvest and anastomosis in the earlier portion of the experimental series.

Ventricular decompression, crossclamping, and cardioplegic arrest. The pulmonary artery pressures remained low at $4 \pm 1 \mathrm{~mm} \mathrm{Hg}$. The aortic root vent pressure was also low at a mean of $-3 \pm 9 \mathrm{~mm}$ Hg. All subjects' hearts arrested within 90 seconds after the institution of cardioplegia. The average pressure of injection was $47.6 \pm 6.9 \mathrm{~mm} \mathrm{Hg}$. The average pressure in the endovascular aortic balloon clamp was $508 \pm 50 \mathrm{~mm} \mathrm{Hg}$.

Myocardial temperature. The blood temperature during $\mathrm{CPB}$ was cooled to $28^{\circ} \mathrm{C}$ and the temperature of the cardioplegic solution was $10^{\circ} \mathrm{C}$. The mean left and right ventricular temperatures during CPB were $17^{\circ} \pm 1^{\circ} \mathrm{C}$. At the conclusion of aortic crossclamping, the myocardium was rewarmed to $35^{\circ} \pm 1^{\circ} \mathrm{C}$, and the blood temperatures were all rewarmed to above $37^{\circ} \mathrm{C}$.

Angiographic and pathologic examination. Completion angiograms were performed in 18 of the 19 cases (95\%) and all grafts were widely patent (Fig. 3 ). All grafts were studied at autopsy and were noted to be freely patent without gross technical errors.

\section{Discussion}

A number of early preliminary clinical experiences with minimally invasive CABG have been reported, with little follow-up data ${ }^{15-19}$ and without angiographic studies to determine graft patency. The majority of these procedures use minithoracotomies or anterior mediastinotomies and involve operating 
on the beating or fibrillating heart with the aid of CPB. However, the suitability of these procedures for achieving predictable anastomotic patency and adequate myocardial protection remains uncertain. Thus the data reported here on anastomotic patency are important, because they demonstrate that by using cardioplegic arrest with the port-access $C A B G$ system and endovascular aortic clamp (Endoaortic Clamp, Heartport), the surgeon can achieve a highly reproducible ITA-coronary artery anastomosis. Whichever technique is used to preform minimally invasive $\mathrm{CABG}$, the graft patency must compare favorably with the results obtainable with conventional open chest procedures and cardioplegic arrest if the technique is to be of long-term value. The present results suggest that these standards are met when using the port-access CABG system with cardioplegic arrest.

The methods described in this study maintain the fundamental principles of conventional coronary surgery, including myocardial protection and anastomotic accuracy, while fulfilling the potential to limit the pain, complications, and extended recovery associated with median sternotomy. With these methods patients can be offered a minimally invasive procedure with a greater potential for long-term success than is obtainable with catheter-based invasive cardiology procedures or surgical procedures performed on the beating heart. The system and techniques tested in this study provide the surgeon with the technology necessary to perform a meticulous coronary anastomosis on a stationary operative field, which may avoid the inaccuracies inherent with other methods.

The technical aspects of the minimally invasive procedure and use of the EndoCPB System (Heartport) became routine with training and experience. Early on we abandoned use of the operating microscope and began to use a small $2.5 \mathrm{~cm}$ anterior port to facilitate coronary visualization with standard operating loupes. This approach allowed a more conventional suturing technique for the coronary anastomoses. Both myocardial ischemia time and total operative time decreased as our operative experience progressed, even while we advanced to successful bilateral ITA grafts. As has been demonstrated previously, the myocardial protection provided with the EndoCPB System and Endoaortic Clamp is equivalent to that obtained with conventional open chest techniques. ${ }^{22}$ In the current study, cardiac arrest was prompt and myocardial cooling was excellent in each zone of the heart tested,

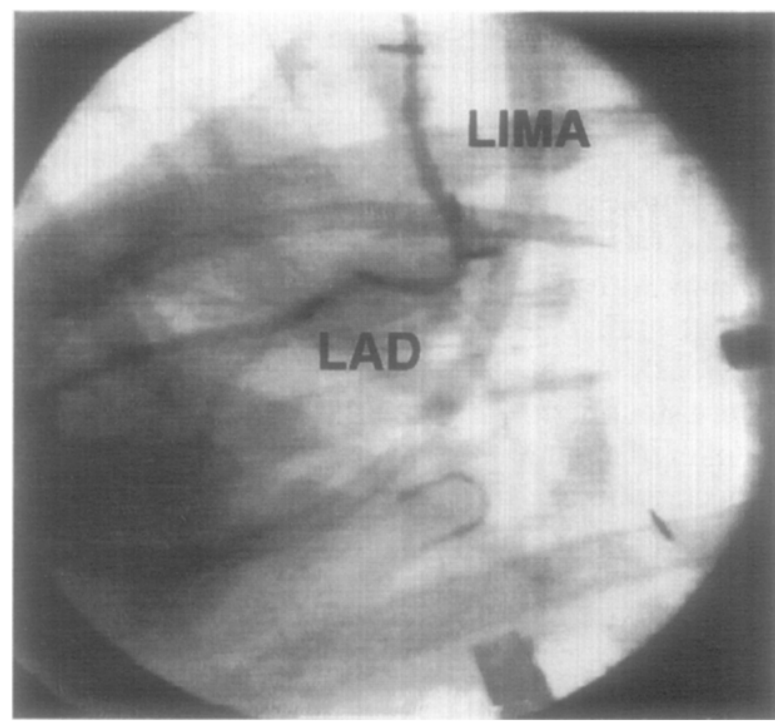

Fig. 3. Still frame from an angiogram obtained after the procedure, demonstrating patency of the left ITA ( $L I M A)$ to the LAD artery.

suggesting uniform delivery of cardioplegic solution to both the left and right ventricles. Likewise, the ability to vent the heart and keep the field dry was very good, because the catheter system allowed gentle suction on the aortic root, proximal to the Endoaortic Clamp, and on the pulmonary artery vent (EPV). Each animal was weaned from CPB without the need for inotropic agents and with excellent myocardial contractility.

Most significantly, postoperative angiography and postmortem autopsy studies revealed $100 \%$ anastomotic patency in each animal in which the anastomosis was completed (18 of 19 animals). This includes every animal after case 4 , when the technique was modified. The anastomosis in case 3 was not completed because of a combination of inadequate takedown length on the ITA and poor visualization while we were using the $0.5 \mathrm{~cm}$ port and operative microscope called for in the initial protocol. This problem highlighted the need for complete ITA takedown and resulted in a protocol change to a slightly larger port with a more conventional anastomosis. Subsequently, both ITA length and anastomotic visualization were excellent in every case. These data suggest that coronary anastomoses can be performed accurately and reproducibly in a minimally invasive fashion using the port-access $\mathrm{CABG}$ and EndoCPB systems. Excellent late graft patency should be achievable with this method.

The limitations of minimally invasive coronary 
surgery may include less ability to provide treatment for complicated, multivessel coronary disease, and the procedure may not be applicable to patients requiring reoperative surgery. Nevertheless, a minimally invasive approach with cardioplegic arrest can be offered as an alternative to catheter-based therapy with the high expectation of achieving excellent graft patency. For example, a patient who previously might have been treated with coronary artery stenting for proximal LAD stenosis may now be offered a minimally invasive ITA bypass. It is our expectation that this procedure will offer patency and late results superior to those obtained either with catheter-based therapy or with surgery on the beating heart. If successful, such a procedure might result in significant cost savings, because the subsequent need for intervention may be diminished.

In summary, minimally invasive CABG with single and bilateral ITAs was successfully and reproducibly performed in a canine model by means of video-assisted ITA takedown, endovascular CPB, cardiac venting, and cardioplegic arrest through an Endoaortic Clamp (Heartport). The operative technique is based on a technologically advanced portaccess CABG system that allows an accurate anastomosis to be performed on a still heart while using small ports for exposure without sternotomy. We anticipate that many of the techniques described in this article may be applicable to CABG in patients in the future. Clinical trials are now in progress.

\section{REFERENCES}

1. Sherman DL, Ryan TJ. Coronary angioplasty versus bypass grafting. Med Clin North Am 1995;79:1085-95.

2. King SB III, Lembo NJ, Weintraub WS, et al. A randomized trial comparing coronary angioplasty with coronary bypass surgery. Emory Angioplasty versus Surgery Trial (EAST). N Engl J Med 1994;331:1044-50.

3. Hamm $\mathrm{CW}$, Reimers $\mathbf{J}$, Ischinger $\mathbf{T}$, et al. A randomized study of coronary angioplasty compared with bypass surgery in patients with symptomatic multivessel coronary disease. German Angioplasty Bypass Surgery Investigation (GABI). N Engl J Med 1994;331:489-95.

4. Edwards HI, Clark RE, Schwartz M. Impact of internal mammary artery conduits on operative mortality in coronary revascularization. Ann Thorac Surg 1994;57:27-32.

5. Loop FD, Lytle BW, Cosgrove DM, et al. Influence of the internal mammary artery on 10 years' survival and other cardiac events. N Engl J Med 1986;314:1-6.

6. Boylan MJ, Lytle BW, Loop FD, et al. Surgical treatment of left anterior descending coronary stenosis: comparison of left internal mammary and venous autograft at 18 and 20 years' follow-up. J Thorac Cardiovasc Surg 1994;107:657-62.
7. Kaiser GC, Davis KB, Fisher LD, et al. Survival following coronary artery bypass grafting in patients with severe angina pectoris (CASS). J Thorac Cardiovasc Surg 1985;89:513-24.

8. Killip T, Passamani E, Davis K, and the CASS Principal Investigators and Their Associates. Coronary artery surgery study (CASS): A randomized trial of coronary bypass surgery-Eight year follow-up and survival in patients with reduced ejection fraction. Circulation 1985;72(Suppl): V102-9.

9. Ryan TJ, Faxon DP, Gunnar RM, et al. Guidelines for percutaneous transluminal coronary angioplasty: a report of the American College of Cardiology/American Heart Association of Diagnostic and Therapeutic Cardiovascular Procedures. Circulation 1988;78:486-502.

10. Dwight J. Coronary bypass or angioplasty? Practitioner 1994; 238:842-6.

11. RITA trial participants. Coronary angioplasty versus coronary bypass surgery: the Randomized Treatment of Angina Trial. Lancet 1993;341:573-80.

12. Rodriguez A, Boulon F, Perez-Balino N, ERACI investigators. Argentine randomized trial of percutaneous transluminal angioplasty versus coronary bypass surgery in multivessel disease (ERACI): in-hospital results and 1 year follow-up. J Am Coll Cardiol 1993;22:1060-7.

13. Leimgruber PP, Roubin GS, Hollman J, et al. Restenosis after successful coronary angioplasty in patients with singlevessel disease. Circulation 1988;77:361-71.

14. Serrupys PW, Luijten HE, Beatt KJ, et al. Incidence of restenosis after successful coronary angioplasty: a time-related phenomenon-a quantitative angiographic study in 342 consecutive patients at $1,2,3$, and 4 months. Circulation 1988;77:361-71.

15. Benetti FJ, Ballester C, Sani G, Doonstra P, Grandjean J. Video assisted coronary bypass surgery. J Card Surg 1995;10: 620-5.

16. Robinson MC, Gross DR, Zeman W, Stedje-Larsen E. Minimally invasive coronary artery bypass grafting: a new method using an anterior mediastinotomy. J Card Surg 1995; 10:529-36.

17. Benetti FJ, Ballester C. Use of thoracoscopy and minimal thoracotomy, in mammary-coronary bypass to left anterior descending artery, without extracorporeal circulation: experience in two cases. J Cardiovasc Surg 1995;36:159-61.

18. Cheung D, Flemma RJ, Mullen DC, et al. An alternative approach to isolated circumflex coronary bypass reoperations. Ann Thorac Surg 1982;33:302-3.

19. Acuff TE, Landreneau RJ, Griffith BP, Mack MJ. Minimally invasive coronary bypass grafting. Ann Thorac Surg 1996;61: 135-7.

20. Stevens JH, Burdon TA, Peters WS. Port-access coronary artery bypass grafting: a proposed surgical method. J Thorac Cardiovasc Surg 1996;111:567-73.

21. Stevens JH, Siegel LC, Mitchell RS, et al. Closed-chest coronary artery bypass with cardioplegic arrest in the dog [abstract]. Circulation 1994;90:251.

22. Schwartz DS, Ribakove GH, Grossi EA, et al. Minimally invasive cardiopulmonary bypass with cardioplegic arrest: technique and equivalent myocardial protection. J Thorac Cardiovasc Surg 1996;111:556-66. 